\title{
Multifactor Assessment of Metabolic Syndrome Risk in Uzbek Children and Adolescents with Obesity
}

\author{
Gulnara N. Rakhimova ${ }^{1,2}, \mathrm{PhD}, \mathrm{ScD}$; Shakhnoza Sh. Azimova ${ }^{1 *}$ \\ ${ }^{1}$ Center for the Scientific and Clinical Study of Endocrinology \\ ${ }^{2}$ Tashkent Institute of Post-Graduate Study, Department of Endocrinology \\ Tashkent, Republic of Uzbekistan
}

\begin{abstract}
Metabolic syndrome (MetS) contributes to early atherosclerotic changes of blood vessels and type 2 diabetes mellitus not only among adults, but among children and adolescents, causing onset and progression of severe diseases resulting in early disablement and death. Multifactor analysis of MetS risk in Uzbek children and adolescents with exogenous-constitutional obesity (ECO) was the purpose of the study. The study included 100 Uzbek children and adolescents with ECO aged from 6 to 16 (mean age $11.7 \pm 0.25$ years) - 54(54.0\%) boys and 46(46.0\%) girls. Prognostic matrix was made up by means of a modification of Bayesian probability by E. Shigan (1986). Mathematical analysis confirmed a high degree of risk for MetS onset and progression in obese patients with disorders of lipid profile and hemodynamics. MetS risk is 8.2 times higher with levels of HDL-C $<1.03 \mathrm{mmol} / \mathrm{l}, 3.6$ times higher in patients with concentrations of $\mathrm{TG} \geq 1.7 \mathrm{mmol} / \mathrm{l}$, and 2 times higher in those with systolic arterial pressure (SAD) values $\geq 130 \mathrm{mmHg}$. The findings from our study confirm a high predictive value of HDL-C levels $<1.03 \mathrm{mmol} / \mathrm{l}, \mathrm{TG} \geq 1.7 \mathrm{mmol} / \mathrm{l}$ and SAD for MetS onset and progression in Uzbek children and adolescents with obesity. Taking into account the integral assessment of MetS risk factors with waist circumference reference values established for the Uzbek pediatric population helped determine risk factors with very high disease dependence, such as atherogenic index $>3.0, \mathrm{HbA} 1 \mathrm{c}>6.7 \%$, and obesity onset before 5 years of age. (Int J Biomed. 2016;6(1):48-52.).
\end{abstract}

Key words: obesity; metabolic syndrome; adolescents; children; prediction.

\section{Introduction}

Metabolic syndrome (MetS) is a cluster of metabolic, hormonal, and clinical disorders closely associated with type 2 diabetes mellitus, and cardiovascular disease. In 2007, the International Diabetes Federation (IDF) established new international criteria for MS diagnosis in children and adolescents [1]. According to some authors, the incidence of MetS diagnosis in children with obesity in compliance with IDF criteria ranges from $16 \%$ to $34 \%$ [2-4]; others report on its diagnosis in half of obese adolescents [5]. Previously, we studied MS prevalence in obese children and adolescents in compliance with tables of waist circumference percentile regression in European-American children and adolescents [1]. The findings from our study demonstrated that MetS occurred in $19 \%$ of Uzbek obese children and adolescents

*Corresponding author: Shakhnoza Sh. Azimova. Center for the Scientific and Clinical Study of Endocrinology. Tashkent, Uzbekistan.E-mail:shahnoz74@yandex.com
[6]. Assessment of risk factors (RFs) governing onset and progression of hormonal-metabolic disorders in childhood, and their ranking by value, significance and controllability is a key task in any study on MetS. Since the search for new significant MetS-RF in obese children and adolescents is vital, multifactor analysis of MS risk in Uzbek children and adolescents with exogenous-constitutional obesity is the purpose of the study.

\section{Material and Methods}

All anthropometric measurements, such as height, body mass, body mass index (BMI), waist circumference (WC), hip circumference (HC) and waist to hip ratio (WHR), were made in 100 Uzbek children and adolescents with exogenousconstitutional obesity (ECO) aged from 6 to 16 (mean age $11.7 \pm 0.25$ years $)-54 / 54.0 \%$ boys and $46 / 46.0 \%$ girls. BMI values within the range of $85^{\text {th }}-97^{\text {th }}$ percentiles were considered as overweight; those above the $95^{\text {th }}$ were assessed as obese (2007 WHO Z-curves). WC values were assessed 
by means of percentile tables developed for the age and sex, according to reference values in the representative sample of Uzbek children and adolescents [7]. Arterial pressure was measured in the morning and in the evening with subsequent assessment of values by age, sex and height percentiles [8]. The glucose oxidase method was used to measure fasting glucose and a 2-hour oral glucose tolerance test (OGTT) in the capillary blood; all examinees underwent OGTT with per oral administration of $1.75 \mathrm{~g}(\max 75 \mathrm{~g})$ of glucose per $1 \mathrm{~kg}$ of weight. The modified colorimetric procedure of Flückiger and Winterhalter was employed for estimating $\mathrm{HbAlc}$ levels. Serum concentrations of total cholesterol (TC), high density lipoprotein cholesterol (HDL-C) and triglycerides (TG) were measured by enzymatic colorimetric method by means of reagent kits supplied by Human, GeselFürBiochemica Und DiagnosticambH (Wiesbaden, Germany). RIA was used to measure concentrations of sex-steroid binding globulin (SSBG), and fasting and $2 \mathrm{~h} \mathrm{IRI} \mathrm{(GTT)} \mathrm{(Immunotech,} \mathrm{Czech}$ Republic). The HOMA-IR index was used to assess insulin resistance (IR). "Micral-test-II" test-strips (Roche, Germany) were used to assess microalbuminuria (MAU).

A modification of the Bayesian probability method for standardization of intensive parameters [9] with calculation of prognosis and weighted indices, and with standardized intensive and integrated parameters underlies the development of a prognostic matrix. To make the matrix we obtained comparable parameters of the predicted phenomenon by gradations of the most significant factors. The significance of the factors and their gradations was established by means of a relative risk (RR) parameter, or so-called weighting factor. RR was considered low at 2, moderate at the range from 2 to 3 , high at $\geq 3$. In addition, we calculated etiological fraction (EF) and rank for each MetS-RF. The etiological dependence was considered practically complete with $1<\mathrm{RR}<1.4$ and $\mathrm{EF}<80$; it was very high at $2<\mathrm{RR}<3.2$ and $\mathrm{EF}$ in the range between 56 and 66 , moderate at $1.5<\mathrm{RR}<2$ and $\mathrm{EF}$ in the range between 33 and 55, and small at $1<\mathrm{RR}<1.4$ and $\mathrm{EF}<33$ [10].

\section{Results and Discussion}

To assess the value of MetS-RFs in Uzbek children and adolescents with ECO we developed a prognostic risk matrix (Table 1). Mathematical analysis confirmed a high degree of risk for MS onset and progression in obese patients with disorders of lipid profile and hemodynamics. MetS risk is 8.2 times higher with levels of HDL-C $<1.03 \mathrm{mmol} / \mathrm{l}(69.0 \pm 8.5), 3.6$ times higher in patients with concentrations of $\mathrm{TG} \geq 1.7 \mathrm{mmol} / \mathrm{l}(33.8 \pm 9.4)$, and 2 times higher in those with systolic arterial pressure (SAD) values $\geq 130 \mathrm{mmHg}(50.0 \pm 24.5)$. Fasting glycemia demonstrated a rather low predictive value.

The atherogenic index (AI) $>3.0(47.1 \pm 15.2)$, improving the prognosis by more than by 3 times, turned out to be the most significant MetS-RF in Uzbek obese children. HbAlc $>6.7 \%(60.0 \pm 23.1$ and obesity onset age over 10 years are newly established and significant MS risk factors in Uzbek children and adolescents, with obesity prognosis increasing by more than 2.5 times. It should be noted that $\mathrm{SAD} \geq 139 \mathrm{mmHg}$ increases MetS risk by 2 times $(50.0 \pm 24.5)$. Obesity duration more than $5-10$ years $(34.1 \pm 18.8)$, HOMA index $>3<75^{\text {th }}$ percentile $(50.0 \pm 30.2)$, and total cholesterol level $\geq 5.2 \mathrm{mmol} / 1$ (34.3 \pm 21.5$)$ increase MetS risk by almost 2 times.

$\mathrm{RR}$ and $\mathrm{EF}$ were used to determine a rank for each MetS-RF (Table 2). Analysis of relative risk and etiological fraction of MetS-RFs demonstrated that almost complete dependence is associated with HDL-C $<1.03 \mathrm{mmol} / \mathrm{l}(\mathrm{RR}=8.16$; $\mathrm{EF}=87.75 \%$ ). Very high dependence of the disease was found to be associated with $\mathrm{TG} \geq 1.7 \mathrm{mmol} / \mathrm{l}(\mathrm{RR}=3.6 ; \mathrm{EF}=72.30 \%)$ and $\mathrm{AI}>3.0(\mathrm{RR}=3.11 ; \mathrm{EF}=67.85 \%)$. MetS high dependence can be seen with $\mathrm{HbAlc}>6.7 \%(\mathrm{RR}=2.60 ; \mathrm{EF}=61.54 \%)$ and obesity onset age over 10 years $(\mathrm{RR}=2.56$; $\mathrm{EF}=60.94 \%)$. MS moderate dependence is observed with $\mathrm{SAD} \geq 130 \mathrm{mmHg}$, obesity duration 5-10 years, HOMA $>3^{\text {rd }}<75^{\text {th }}$ percentile, and total cholesterol $\geq 5.2 \mathrm{mmol} / \mathrm{l}$.

According to T. Bokova [2], biological factors, such as abdominal obesity $(\mathrm{RR}=4.77, \mathrm{EF}=79.0 \%)$, insulin resistance $(\mathrm{RR}=4.04, \mathrm{EF}=75.2 \%)$, hyperglycemia $(\mathrm{RR}=3.20$, $\mathrm{EF}=68.0 \%$ ), dislipidemia manifesting in the $\mathrm{TG}$ increase and decrease in HDL-C $(\mathrm{RR}=2.60, \mathrm{EF}=61.5 \%$ and $\mathrm{RR}=2.40$, $\mathrm{EF}=60.0$, respectively), small weight at birth (less than $2,500 \mathrm{~g})(\mathrm{RR}=1.90, \mathrm{EF}=47.4 \%)$, hyperuricemia $(\mathrm{RR}=1.85$, $\mathrm{EF}=45.9 \%)$, and thyroid enlargement $(\mathrm{RR}=1.75, \mathrm{EF}=42.9 \%)$, prevailed among the hardly controllable risk factors for MS in children and adolescents with very high, high, and moderate dependence in the Russian population. A high degree of obesity $\left(\mathrm{BMI}>30 \mathrm{~kg} / \mathrm{m}^{2}\right) \quad(\mathrm{RR}=2.7, \quad \mathrm{EF}=63.0 \%)$, obesity duration more than 5 years $(\mathrm{RR}=1.74, \mathrm{EF}=42.5 \%)$, eating behavior disorder(night eating syndrome) $(\mathrm{RR}=1.52, \mathrm{EF}=34.3 \%)$, and teenage years $(12-16$ years of age) $(\mathrm{RR}=1.50, \mathrm{EF}=3.3 \%)$ are the controllable risk factors for high and moderate dependence. Our findings are consistent with those obtained by T. Bokova [2] in many respects.

The findings from our study demonstrate that $\mathrm{WC}$ is a poor contributor to MS prediction in obesity both in calculation in accordance with the WC European percentile tables for children and adolescents [5] and in accordance with WC percentile tables for Uzbek children and adolescents [8]. This finding can be probably associated with the fact that initially most $(97 \%)$ patients with $\mathrm{ECO}$ had $\mathrm{WC}>97^{\text {th }}$ percentile. In addition, mean WC values in adolescents with $\mathrm{ECO}$ and MetS and with ECO but without MetS had no significant differences.

Thus, integral assessment of MetS-RFs for Uzbek obese children and adolescents demonstrated that those with low HDL-C, high TG, high AI, high glycated hemoglobin, obesity onset age over 10 years, and high SAD are at the highest risk.

\section{Conclusion}

The findings from our study confirm a high predictive value of HDL-C levels $<1.03 \mathrm{mmol} / \mathrm{l}(\mathrm{RR}=8.16), \mathrm{TG} \geq 1.7$ $\mathrm{mmol} / \mathrm{l}(\mathrm{RR}=3.61)$ and $\mathrm{SAD}(\mathrm{RR}=2.4)$ for $\mathrm{MS}$ onset and progression in Uzbek children and adolescents with obesity. Taking into account the integral assessment of MetS-RFs with WC reference values established for the Uzbek pediatric population helped determine RFs with very high disease dependence, such as $\mathrm{AI}>3.0 \quad(\mathrm{RR}=3.100), \mathrm{HbA} 1 \mathrm{c}>6.7 \%$ $(R R=2.60)$, and obesity onset before 5 years of age $(R R=2.56)$. 
Table 1.

Prognostic matrix for multifactor assessment of MetS risk in Uzbek children and adolescents with ECO

\begin{tabular}{|c|c|c|c|c|c|c|c|}
\hline \multirow{2}{*}{ Factors } & \multirow{2}{*}{ Factor gradation } & $\mathrm{M}, \%$ & \multirow{2}{*}{ SIP } & \multirow{2}{*}{$\mathrm{RR}$} & \multirow{2}{*}{ IRA } & \multirow{2}{*}{ Min } & \multirow{2}{*}{ Max } \\
\hline & & 29.0 & & & & & \\
\hline \multirow{2}{*}{ Sex } & Boys & 25.9 & 0.894 & \multirow{2}{*}{1.01} & 0.90 & \multirow{2}{*}{0.90} & \multirow{2}{*}{0.91} \\
\hline & Girls & 26.1 & 0.900 & & 0.91 & & \\
\hline \multirow{3}{*}{ The Tanner stage } & I & 10.0 & 0.345 & \multirow{3}{*}{1.38} & & \multirow{3}{*}{1.15} & \multirow{3}{*}{1.59} \\
\hline & II-III & 24.1 & 0.832 & & 1.15 & & \\
\hline & IV-V & 33.3 & 1.149 & & 1.59 & & \\
\hline \multirow{3}{*}{ BMI, kg/m² } & $<85^{\text {th }}$ percentile & 0.0 & 0.000 & \multirow{3}{*}{1.41} & 0.00 & \multirow{3}{*}{0.00} & \multirow{3}{*}{2.18} \\
\hline & $85^{\text {th }}-97^{\text {th }}$ percentile & 40.0 & 1.379 & & 1.94 & & \\
\hline & $>97^{\text {th }}$ percentile & 28.4 & 0.980 & & 1.38 & & \\
\hline \multirow{3}{*}{$\mathrm{WC}, \mathrm{cm}$} & $>75^{\text {th }} \leq 90^{\text {th }}$ percentile & 0.0 & 0.000 & \multirow{3}{*}{1.29} & 0.00 & \multirow{3}{*}{$\begin{array}{c}0.0 \\
0\end{array}$} & \multirow{3}{*}{1.49} \\
\hline & $>90^{\text {th }} \leq 97^{\text {th }}$ percentile & 25.8 & 1.149 & & 1.15 & & \\
\hline & $>97^{\text {th }}$ percentile & 33.3 & & & 1.49 & & \\
\hline & Normal & 22.6 & 0.779 & & 1.09 & & \\
\hline $\mathrm{WC} / \mathrm{HC}$ & Pathology & 31.6 & 1.089 & 1.40 & 1.52 & 0.09 & 1.52 \\
\hline Capillary blood fasting glycemia, & $\geq 5.0$ & 30.8 & 1.061 & 122 & 1.29 & 106 & 120 \\
\hline $\mathrm{mmol} / 1$ & $<5.0$ & 25.3 & 0.872 & 1.22 & 1.06 & 1.00 & 1.29 \\
\hline & $<5,9$ & 24.4 & 0.841 & & 2.19 & & \\
\hline $\mathrm{HbA} 1 \mathrm{c}, \%$ & $\geq 5.9-6.7$ & 23.1 & 0.796 & 2.60 & 2.07 & 2.07 & 5.38 \\
\hline & $>6.7$ & 60.0 & 2.069 & & 5.38 & & \\
\hline Total cholecterol mmol/ & $\geq 5.2$ & 34.3 & 1.182 & 150 & 1.88 & 118 & 188 \\
\hline Iotal cholesterol, mmol/1 & $<5.2$ & 21.5 & 0.743 & 1.59 & 1.18 & 1.18 & 1.88 \\
\hline $\mathrm{HDI} / \mathrm{C} \mathrm{mmol} / 1$ & $\geq 3.5$ & 24.0 & 0.828 & 111 & 0.92 & 092 & 102 \\
\hline $\mathrm{HDL}-\mathrm{C}, \mathrm{mmol} / \mathrm{I}$ & $<3.5$ & 26.7 & 0.920 & 1.11 & 1.02 & 0.92 & 1.02 \\
\hline & $<1.03$ & 69.0 & 2.378 & & 19.41 & & \\
\hline LDL-C, mmol/I & $\geq 1.03$ & 8.5 & 0.291 & 8.16 & 2.38 & 2.38 & 19.41 \\
\hline & $\geq 1.7$ & 33.8 & 1.166 & & 4.21 & & \\
\hline $\mathrm{IG}, \mathrm{mmol} / \mathrm{I}$ & $<1.7$ & 9.4 & 0.323 & 3.61 & 1.17 & 1.17 & 4.21 \\
\hline & $>3.0$ & 47.1 & 1.623 & & 5.04 & & \\
\hline Atherogenic index & $\leq 3,0$ & 15.2 & 0.522 & 3.11 & 1.62 & 1.62 & 5.04 \\
\hline & $\geq 130$ & 50.0 & 1.724 & 204 & 3.52 & 172 & 352 \\
\hline systolic arterial pressure, mmHg & $<130$ & 24.5 & 0.844 & 2.04 & 1.72 & 1.12 & 3.52 \\
\hline Diastolic arterial pressure, & $\geq 85$ & 33.3 & 1.149 & 132 & 1.52 & 115 & 152 \\
\hline $\mathrm{mmHg}$ & $<85$ & 25.3 & 0.872 & 1.32 & 1.15 & 1.15 & 1.52 \\
\hline Fasting IRI mcI/ml & $>25.0$ & 38.5 & 1.326 & 132 & 1.76 & 133 & 176 \\
\hline Fasting IRI, mcU/mI & $\leq 25.0$ & 29.0 & 1.001 & & 1.33 & 1.33 & 1.16 \\
\hline 2h IRI, $\mathrm{mcU} / \mathrm{ml}$ & $>25.0$ & 35.0 & 1.207 & & 1.48 & 121 & \\
\hline & $\leq 25.0$ & 28.6 & 0.985 & 1.23 & 1.21 & 1.21 & 1.48 \\
\hline & $<3^{\text {rd }}$ percentile $(0.47 / 0.45)$ & 0.0 & 0.000 & & 0.00 & & \\
\hline HOMA_IR & $>3^{\text {rd }}$ percentile $<75^{\text {th }}$ percentile $(0.74 / 1.0)$ & 50.0 & 1.724 & & 2.86 & & \\
\hline HUMA-IR & $>75^{\text {th }}$ percentile $<97^{\text {th }}$ percentile $(1.23 / 1.8)$ & 35.7 & 1.232 & 1.66 & 2.04 & 0.00 & 2.86 \\
\hline & $>97^{\text {th }}$ percentile $(1.23 / 1.80)$ & 30.2 & 1.041 & & 1.72 & & \\
\hline MAU mo/1 & $<30$ & 25.0 & 0.862 & 120 & 1.03 & 103 & 124 \\
\hline MAU, mg/I & from 30 to 100 & 30.0 & 1.034 & 1.20 & 1.24 & 1.03 & 1.24 \\
\hline
\end{tabular}

$M$ - a parameter per 100 children with obesity, SIP-standardized intensive parameter, RR-relative risk, IRA-integrated risk assessment. 
Table 1.

Prognostic matrix for multifactor assessment of MetS risk in Uzbek children and adolescents with ECO (continued)

\begin{tabular}{|c|c|c|c|c|c|c|c|}
\hline \multirow{2}{*}{ Factors } & \multirow{2}{*}{ Factor gradation } & $\mathrm{M}, \%$ & \multirow{2}{*}{ SIP } & \multirow{2}{*}{$\mathrm{RR}$} & \multirow{2}{*}{ IRA } & \multirow{2}{*}{ Min } & \multirow{2}{*}{ Max } \\
\hline & & 29.0 & & & & & \\
\hline \multirow{2}{*}{ Heredity by diabetes mellitus } & Yes & 28.9 & 0.998 & \multirow{2}{*}{1.20} & 1.19 & \multirow{2}{*}{1.00} & \multirow{2}{*}{1.19} \\
\hline & No & 24.2 & 0.834 & & 1.00 & & \\
\hline \multirow{2}{*}{ Heredity by arterial hypertension } & Yes & 28.6 & 0.985 & \multirow{2}{*}{1.13} & 1.11 & \multirow{2}{*}{0.99} & \multirow{2}{*}{1.11} \\
\hline & No & 25.3 & 0.873 & & 0.99 & & \\
\hline \multirow{2}{*}{ Heredity by obesity } & Yes & 31.0 & 1.067 & \multirow{2}{*}{1.38} & 1.47 & \multirow{2}{*}{1.07} & \multirow{2}{*}{1.47} \\
\hline & No & 22.4 & 0.773 & & 1.07 & & \\
\hline \multirow{3}{*}{ Obesity onset age } & under 5 years & 29.2 & 1.006 & \multirow{3}{*}{2.56} & 2.57 & \multirow{3}{*}{1.72} & \multirow{3}{*}{4.41} \\
\hline & 5-10 years & 19.6 & 0.675 & & 1.72 & & \\
\hline & over 10 years & 50.0 & 1.724 & & 14.41 & & \\
\hline \multirow{3}{*}{ Obesity duration } & under 5 years & 1.88 & 0.647 & \multirow{3}{*}{1.82} & 1.18 & \multirow{3}{*}{1.18} & \multirow{3}{*}{2.14} \\
\hline & $5-10$ years & 34.1 & 1.177 & & 2.14 & & \\
\hline & over 10 years & 22.2 & 0.766 & & 1.40 & & \\
\hline
\end{tabular}

$M$ - a parameter per 100 children with obesity, SIP-standardized intensive parameter, $R R$ - relative risk, IRA-integrated risk assessment.

Table 2.

Risk factors by value for MetS onset in Uzbek children and adolescents with ECO

\begin{tabular}{|l|c|c|c|}
\hline Risk factors & RR & EF, $\%$ & Rank \\
\hline HDL-C $<1.03 \mathrm{mmol} / 1$ & 8.16 & 87.75 & 1 \\
\hline TG $\geq 1.7 \mathrm{mmol} / 1$ & 3.61 & 72.30 & 2 \\
\hline $\mathrm{AI}>3.0$ & 3.11 & 67.85 & 3 \\
\hline HbA1c $>6.7 \%$ & 2.60 & 61.54 & 4 \\
\hline Obesity onset age over 5 years & 2.56 & 60.94 & 6 \\
\hline Systolic arterial pressure & 2.04 & 50.98 & 7 \\
\hline Obesity duration more than 10 years & 1.82 & 45.05 & 8 \\
\hline HOMA-IR $>3^{\text {rd }}$ percentile $<75^{\text {th }}$ percentile & 1.66 & 39.76 & 9 \\
\hline Total cholesterol $\geq 5.2$ mmol $/ 1$ & 1.59 & 37.11 & 10 \\
\hline BMI $85^{\text {th }}-97^{\text {th }}$ percentile $>97^{\text {th }}$ percentile & 1.41 & 29.08 & 11 \\
\hline
\end{tabular}

\section{Competing interests}

The authors declare that they have no competing interests.

\section{References}

1. Zimmet P, Alberti KG, Kaufman F, Tajima N, Silink M, Arslanian S, et al. The metabolic syndrome in children and adolescents-an IDF consensus report. Pediatric Diabetes.2007; 8(5):299-306.

2. Bokova TA. Metabolic syndrome in children: peculiarities of formation and clinical course, approaches to diagnosis, prevention and treatment. Abstract of ScD Thesis. Moscow; 2014. [in Russian].
3. Leontieva IV. Diagnosis and treatment of metabolic syndrome in pediatric practice. Pediatrics. 2011; 2:13-23 [in Russian].

4. Sinitsyn P.A. Metabolic syndrome in children and adolescents. Clinical-pathogenetic parallels. Abstract of ScD Thesis. Moscow; 2011. [in Russian].

5. Rakhimova GN, Azimova ShSh. Integral assessment of risk factors for metabolic syndrome in children and adolescents with obesity. International Endocrinological Journal. 2012; (43):77-81 [in Russian].

6. Azimova ShSh, Rakhimova GN. Determination of metabolic syndrome risk by waist circumference in Uzbek children and adolescents. Patent No. DGU 02583 (2012).

7. Azimova Sh, Rakhimova G. Waist circumference 
percentiles in a nationally representative sample of 7-18 years old Uzbek children and adolescents. Medical and Health Science Journal. 2013; 14 (3):123-27.

8. Update on the 1987 Task Force Report on High Blood Pressure in Children and Adolescents: a working group report from the National High Blood Pressure Education Program. National High Blood Pressure Education Program Working
Group on Hypertension Control in Children and Adolescents. Pediatrics. 1996; 98 (4 Pt 1): 649-58.

9. Shigan EN. Methods for prediction and modeling in social-hygienic studies. M.: Meditsina; 1986. [in Russian]. 10. Babanov S.A., Vorobyova E.V., Gailis P.V., Agarkova I.A. Epidemiology of non-infectious diseases: problems of this stage. Profilakt Meditsina 2011; (3):11-14 [in Russian]. 